\title{
MÚLTIPLAS CENTRALIDADES DO LAZER NOTURNO NA CIDADE DE SÃO JOSÉ DO RIO PRETO - SP
}

MULTIPLE CENTRALITIES THE NIGHT LEISURE IN THE CITY OF SÃO JOSÉ DO RIO PRETO $-S P$

Aylé de Mello Gomes ${ }^{1}$

\section{RESUMO}

O presente trabalho procura identificar a oferta de diversão noturna presente na cidade de São José do Rio Preto, suas lógicas econômicas e a possível formação de áreas centrais noturnas. Ainda nesse campo, procuramos identificar as práticas espaciais dos consumidores de diversão noturna (que são sobretudo jovens), suas formas de interação e os impactos das novas tecnologias. A articulação entre formação da cultura juvenil, cultura de consumo, o uso de redes sociais envolvem diferentes temáticas que sustentam as práticas juvenis nas cidades que acarretam o uso do espaço urbano. São José do Rio Preto é uma cidade que apresenta disparidades significativas no âmbito socioeconômico, disparidades observadas a partir da valorização imobiliária e da oferta de bens e serviços, onde estabelecimentos de diversão noturna estão inclusos.

Palavras-chave: Diversão Noturna; Consumo; Sociabilidade.

\begin{abstract}
The present work focuses on identifying the nightlife offer present in the city of São José do Rio Preto, these economic logics and the possible formation of central areas at night. Even in this sense, we seek to identify spatial practices of consumers of nightlife (which are mainly young people), its forms of interaction and the impacts of new technologies. The relationship between the formation of the youth culture, consumer culture, the use of social networks involves different themes that underpin youth practices in cities that entail the use of urban space. São José do Rio Preto is a city that offers significant disparities in the socio-economic sphere, disparities observed from the real estate valuation and the supply of goods and services, where nightlife establishments are included.
\end{abstract}

Keywords: Nightlife; Consumption; Sociability.

\footnotetext{
${ }^{1}$ Universidade Estadual Paulista "Júlio de Mesquita Filho” (UNESP).
} 


\section{INTRODUÇÃO}

A presente pesquisa faz parte do Projeto Temático: "Lógicas Econômicas e Práticas Espaciais Contemporâneas: Cidades Médias e Consumo", financiado pela Fundação de Amparo à Pesquisa do Estado de São Paulo (FAPESP), desenvolvido pelo Grupo de Pesquisa e Produção do Espaço e Redefinições Regionais (GASPERR) da Universidade Estadual Paulista "Júlio de Mesquita Filho" (UNESP).

A pesquisa do projeto temático volta-se aos processos de estruturação e reestruturação das cidades médias, a partir da oferta e das práticas espaciais dos citadinos ao consumo. Portanto, o sub-projeto "Múltiplas Centralidades do Lazer Noturno na cidade de São José do Rio Preto - SP”, proporciona um panorama da cidade estudada no que se refere a oferta de diversão noturna, suas lógicas econômicas, uma possível formação de áreas centrais noturnas bem como as práticas espaciais dos consumidores nos estabelecimentos de diversão noturna (bares, casas noturnas, pubs, etc.).

Também ressaltamos que a pesquisa procura demonstrar como as interações de sociabilidade têm sido modificadas por meio do uso de redes sociais, portanto relacionando as áreas centrais de diversão noturna com a interatividade online.

\section{PROCEDIMENTOS METODOLÓGICOS}

A pesquisa foi realizada através de levantamentos bibliográficos, com leituras de diversas áreas que contribuem para o entendimento das dinâmicas que objetivamos encontrar, tais como, Sociologia, História, Antropologia e Geografia. Também foi realizada uma pesquisa online em redes sociais e sites de busca, para identificação dos principais estabelecimentos de diversão noturna e consequentemente um mapeamento destes.

Por fim realizamos trabalhos de campo na cidade para entrevistas com donos e/ou gerentes dos estabelecimentos, bem como com seus consumidores, o que nos proporcionou uma compreensão das dinâmicas nos centros de diversão noturna.

\section{DESENVOLVIMENTO}

Procuraremos aqui demonstrar a relação entre a formação da cultura juvenil, cultura de consumo, o uso de redes sociais e a ocupação do espaço urbano, pois esta articulação envolve diferentes temáticas que sustentam as práticas juvenis nas cidades. Pretendemos relacionar 
estes pontos com o observado em São José do Rio Preto, para posteriormente apresentar as áreas que centralizam a diversão noturna e as práticas sociais que lhe são correlatas.

Segundo Sposito (1993), a juventude é uma construção histórico-social. Inicialmente, pode-se considerar que este momento da vida é traduzido pelo intervalo - cuja variação temporal é histórica - entre a posse de condições de reprodução biológica (sexual) e de produção social (maturidade física e mental para o trabalho) e o reconhecimento por parte da sociedade de sua habilitação plena para o desempenho dessas atividades na vida adulta. Por essas razões, a autora afirma que a caracterização do jovem deve ser traçada sob o ponto de vista relacional, ou seja, a partir de uma forma peculiar de relação que ele mantém com o mundo adulto e, consequentemente, de sua busca de distância do universo infantil.

Nessa passagem entre o universo infantil e o universo adulto, a fase de da juventude é marcada também por uma ampliação de suas esferas de circulação, atuação e apropriação na/da cidade, de forma mais autônoma em relação à família. Desse modo, a juventude remete a um conjunto diversificado de sujeitos sociais portadores de espacialidades diferenciais na cidade em relação com o contexto de interação social que possuem a sua disposição, nos lugares em que vivem.

A produção, a socialização, o consumo e as práticas culturais incidem sobre usos diferenciais do espaço e espelham os ritmos desiguais que caracterizam não só as relações entre as classes, mas a dinâmica das gerações e dos grupos de idade, as relações entre os gêneros, os ciclos de vida no trabalho e no lazer. Enfim, conjunto intenso de relações que projetam em um só presente diversas temporalidades, a cidade pode se tornar, também, a expressão de conflitos multifacetados, capazes de oferecer novas possibilidades de apropriação do tecido urbano (SPOSITO, 1993, p. $162)$.

Pais (1993) traz um debate sobre diferenciação nas fases de vida, apresentando duas correntes sociológicas que estudam a juventude: a geracional e a classista.

Para a primeira corrente, a juventude é tida como composta por sujeitos que pertencem a uma determinada fase de vida, relacionando sua faixa etária, aspectos uniformes e homogêneos, que a caracterizam, gerando, assim, uma cultura juvenil que se opõe a cultura da vida adulta. A corrente geracional, se apoia em duas teorias: a da socialização - para a qual os conflitos intergeracionais são vistos, na maioria dos casos, como disfunções nos processos de socialização da juventude tomada no sentido de fase de vida, e a segunda teoria desta corrente é a das gerações, para a qual só existem a descontinuidades intergeracionais porque existem gerações. 
A corrente geracional tem para si que na formação de sua base a juventude possui descontinuidades intergeracionais, enquanto uma geração social, isto é, "o fato de cada geração social só ficar determinada mediante uma auto-referência a outras gerações, das quais se vê distinta. Pais (1993) traz algumas características da juventude na visão da corrente geracional:

1) Constituído por indivíduos cujas idades se concentram, com alguns possíveis desvios individuais, dentro de um intervalo relativamente estreito; 2) cujos membros serão portadores do sentimento comum de se encontrarem coletivamente em presença, na sociedade, de certos grupos distintos do seu pela idade e formados quer por indivíduos mais velhos quer eventualmente por indivíduos mais novos; 3) nos membros do grupo manifestar-se-á igualmente o sentimento, de que, relativamente aos grupos sociais mais velhos ou mais novos em cuja presença eles a si mesmos se vêm, existem, além de significativas diferenças etárias, não menos significativas diferenças nas respectivas referências sociais e culturais (informação, valores, interesses, problemas, projetos, etc.) (PAIS, 1993, p. 49).

Portanto para a corrente geracional, a existência de uma cultura juvenil seria uma forma de oposição à cultura de outras gerações, no caso, das gerações adultas. Defende-se ainda que os sujeitos vivenciem o mundo (experiências, situações, problemas, etc), como membros de uma geração, visto que este é compartilhado com outros indivíduos da mesma geração.

A corrente classista toma a juventude como um conjunto social necessariamente diversificado, constituído por diferentes classes sociais, situações econômicas, interesses, ocupações, estilos, etc. Nesse sentido, Pais (1993), apresenta que a reprodução social é vista em termos de reprodução de gênero, de raça, enfim, de classes sociais, onde o que determinaria o futuro econômico é o sistema educativo e a condição social dos próprios jovens. Assim, podemos considerar que as culturas juvenis de jovens da classe trabalhadora sejam entendidas de forma antagônica à cultura da classe dominante.

Pais (2003), contudo oferece uma terceira via de interpretação, em que tanto aspectos gerais da juventude, como as questões de continuidade e descontinuidade geracional, quanto aspectos que a diversificam são considerados para compreender as juventudes contemporâneas. Este autor defende uma abordagem pluralista.

Também é importante ressaltar, para a análise que pretendemos fazer, a questão da governança da cultura (pelas formas de comunicação, rádio e TV), apresentada por Hall (1997), em que novas condutas, ações e práticas sociais nos são reguladas, colocando assim como tendência a homogeneização da cultura. 
Outro fator interessante é a questão de anúncios publicitários, que trazem à tona o ideal de vida do jovem urbanizado, tomando como referência a experiência metropolitana. Segundo Sposito (1993), a indústria da moda absorveu rapidamente o estilo de vida jovem rebelde, lançando-o como tendência no mercado.

A partir da metade dos anos 1960, as transformações internacionais que vinham ocorrendo na moda e a consolidação do sucesso nacional da Jovem Guarda acarretariam uma grande mudança na imagem estabelecida pela publicidade. Gradualmente, veríamos acontecer uma "juvenilização" dos anúncios publicitários. Assim como os gostos começariam a se alterar, em decorrência das mudanças na sociabilidade, os periódicos também passariam por mudanças; havia um novo público interessado em consumir um novo tipo de informação. Percebendo, então, que havia um público jovem consumidor constituindo-se no Brasil e compreendendo que este fenômeno relacionava-se com a ocupação do espaço urbano como local de sociabilidade pelos adolescentes no contexto internacional (SPOSITO, 1993, p. 163).

Portanto, entendemos que a estética que se elabora na imagem "parece, ao que tudo indica poder ser como uma linguagem que impulsiona e favorece a formação de pequenos grupos ou tribos" (CASTRO, 1988, p. 33). A eficácia da aparência assume a função de identificar, de agrupar. Nas grandes cidades, em que os sujeitos se tornam anônimos na multidão, torna-se possível ser visível e reconhecido e às vezes abordado por aqueles que compartilham as mesmas referências, mas ainda não se conhecem, ou mesmo por aqueles que contestam tais referências (o que pode ser de forma violenta).

Desta maneira, as práticas espaciais nas cidades podem ser lidas enquanto modos de fazer, de enunciação e significação da cultura, pois “[...] não basta ser autor de práticas sociais; é preciso que essas práticas sociais tenham significado para aquele que as realiza" (CERTEAU, 1995, p. 141).

A abordagem de Almeida e Tracy (2003) sobre territorialidade nômade dos jovens da zona sul do Rio de Janeiro oferece elementos importantes para a nossa análise, pois segundo as autoras, as trajetórias tornam-se um traço característico da ocupação noturna. "Essas trajetórias são delineadas por multidões de jovens que fazem do deslocamento um fim em si” (ALMEIDA; TRACY, 2003, p. 18).

A caracterização do "nomadismo", como modo de ser específico está ligado a territorialidade, ou seja, a espacialização da experiência (social e subjetiva) em termos de deslocamento e não de fixação, como é o caso das existências sedentárias. Em vez de fixar-se em um ponto do espaço, transformando-o em um "lugar", como faz o sedentário, o nômade tem um território, segue trajetos contingentes, "vai de um ponto a outro" (ALMEIDA; TRACY, 2003, p. 41).

Portanto, ao tomarmos por base as contribuições de Almeida e Tracy (2003), os deslocamentos na noite conduzem a uma espacialidade dinâmica, na qual a ida a lugares 
específicos é substituída por modos diversos de circulação na noite. Em São José do Rio Preto, pudemos observar (e confirmamos por meio da enquete realizada) que os consumidores de diversão noturna frequentam, numa mesma noite, mais de um local.

Desse modo, podemos reproduzir a multiplicidade de práticas contidas na noite, que por vezes recaem na influência das práticas e imagens que chegam a partir das metrópoles.

"A metrópole é policêntrica, pois difunde-se e prolifera-se em múltiplas direções e polifônica, pois nela novos tipos de culturas fortemente pluralizados e fragmentados espalham-se e transitam" (ALMEIDA; TRACY, 2003, p. 29).

Ainda segundo as autoras, as metrópoles contém "uma pluralidade de culturas (e subculturas, com estilos de vida e identidade a-tempo[rais], vidas estetizadas, modas descartáveis)" (2003, p. 29). As fronteiras destas referências metropolitanas são móveis e plurais e estendem sua influência, sua rede, chegando às cidades médias e pequenas e encontrando a adesão dos jovens nos diversos lugares promovendo rupturas geracionais nos modos de realização de sociabilidade, mas também trazendo modelos de diversão ofertados pelo mercado.

A partir das noções trazidas e com base no observado em campo, pontuamos que a "paisagem social” demonstra uma homogeneidade nos espaços de diversão noturna, seja no âmbito da cultura, preferências musicais, como também quanto aos sujeitos e seu espaço de diversão. Percebemos que os lugares de sociabilidade compreendem "permanência entre os seus iguais", (embora possamos observar um movimento na noite), onde indivíduos, ou grupos de amigos demonstram interesses aproximados, além de faixa etária, nível de estudo, renda aproximada, etc. (o que pudemos extrair através de enquetes realizadas em campo).

A diversão noturna e seu caráter geracional estão atrelados também às novas tecnologias, sendo estas o uso frequente de redes sociais através da internet.

O acesso à internet se dá de maneira cada vez mais acessível, sobretudo, com o uso da telefonia móvel, onde os frequentadores dos bares/restaurantes combinam encontros através das redes sociais como Whatsapp e Facebook, sendo assim observamos que as mensagens instantâneas podem dar uma dinâmica na noite quanto aos lugares de encontro entre amigos.

Assim o uso frequente da internet e das redes sociais exercem uma repercussão nas práticas socioespaciais nas áreas que ofertam lazer noturno, visto que ocorre uma simultaneidade entre o que ocorre nos espaços de diversão noturna e no mundo virtual. Isto porquê os usuários das redes sociais fazem "check-in" (uma opção do Facebook e Instagram 
que comunica a localização/estabelecimento que o usuário se encontra), sendo assim tal prática pode contribuir para reforçar a centralidade das áreas centrais de lazer noturno acarretando uma influência, através das postagens, em outros usuários, podendo atrair outros frequentadores para estes estabelecimentos.

\section{1 Áreas que polarizam diversão noturna}

Neste tópico falaremos das transformações de cidades médias, demonstrando as diferenças entre centro e periferia e as áreas em que identificamos uma parcela de citadinos que possuem um poder aquisitivo maior, o que nos permitirá apontar posteriormente, a partir de alguns processos, as áreas que centralizam a diversão noturna. Contudo, os conceitos de segregação socioespacial e fragmentação socioespacial serão utilizados para evidenciar transformações socioespaciais presentes na cidade.

O conceito de segregação socioespacial se baseia numa separação espacial das diferentes classes sociais no interior das cidades. Mas não apenas como uma diferença de locais, "mas como capacidade de deslocamento e de acesso em relação a pontos estratégicos da rede urbana" (CASTELLS, 2000, p. 262), bem como o acesso desigual que estas mesmas classes possuem em relação aos bens ou meios de consumo coletivo.

Segundo Corrêa (2005), a fragmentação socioespacial é a expressão territorial de novas dinâmicas que envolvem, sobretudo, o processo de segregação socioespacial articulado às novas práticas espaciais reveladoras da segmentação do consumo do espaço urbano, ou seja, não se trata de um processo que supera ou substitui a diferenciação e/ou a segregação socioespacial, mas, por outro lado, contribui por meio do afastamento socioespacial entre as diferenças, no que tange às práticas de habitar e consumir a cidade, para modificar seus respectivos conteúdos, desvalorizando a diferenciação e sobrevalorizando a segregação socioespacial, sobretudo, em sua segunda forma de desdobramento, que é a autossegregação.

Portanto, segregação socioespacial e fragmentação socioespacial são conceitos que exercem um potencial analítico para avançarmos na discussão sobre as cidades médias, como proposto, o caso de São José do Rio Preto.

Segundo Dal Pozzo (2008, p. 20), “o tecido urbano contemporâneo tem passado por transformações morfológicas significativas resultantes da produção de espaços fechados e/ou vigiados, como parte de um processo mais amplo de urbanização difusa". Em amplo sentido, isso significa que, ao longo das últimas décadas, tem-se produzido níveis elevados de 
segregação socioespacial em cidades brasileiras de diferentes portes promovendo uma acentuada separação social e espacial, sobretudo entre os segmentos de alto e baixo poder aquisitivo. A chegada nestas cidades de novas formas de habitat, como os espaços residenciais fechados (para usar uma expressão de DAL POZZO [2008]), tem sido um fator de acirramento das desigualdades socioespaciais.

Como as extensões territoriais das cidades de porte médio são menores e os sistemas viários menos densamente utilizados, há maior facilidade para os deslocamentos dos moradores desses empreendimentos murados e de acesso controlado, de modo a que eles tenham acessibilidade ao conjunto da cidade, mesmo tendo escolhido habitar nesses empreendimentos que, via de regra, tem localização periférica (SPOSITO, 2007).

Conforme afirma Sposito (2007), ao comparar as condições e custos de moradia em loteamentos fechados em aglomerações metropolitanas e em cidades médias, verifica-se que as facilidades observadas nestas em relação àquelas indicam que há elementos para se observar a ocorrência de indícios de fragmentação socioespacial.

[...] por todas essas razões, a periferia segmenta-se, pois a proximidade física de usos diferentes e de conteúdos sociais e culturais diversos não promove, em si, integração, mas gera separação socioespacial, sob a forma de segregação socioespacial ou de fragmentação urbana (SPOSITO, 2007, p. 8).

Ainda segundo Sposito (2007), todos estes estudos apontam para a redefinição das relações entre o centro e a periferia nas cidades de porte médio. Até os anos de 1970 e 1980, a circulação intra-urbana nessas cidades articulava-se em torno de um centro principal, compondo estruturas fortemente integradas a uma única área importante de concentração de estabelecimentos comerciais e de serviços. Nos últimos vinte anos, observou-se multiplicação de áreas de concentração dessas atividades (eixos comerciais, centros comerciais em bairros de bom poder aquisitivo e shopping centers), bem como se verificou o fenômeno de diversificação delas, acompanhado de segmentação dos mercados consumidores, segundo diferentes padrões de consumo e maior ou menor facilidade para se locomover por automóvel.

Sendo assim, também destacaremos os empreendimentos de diversão noturna, que vêm acompanhando estas lógicas, sobretudo pela proximidade com áreas de loteamentos fechados e de expansão da cidade a partir de bairros de alto status social. "A diversificação das escolhas locacionais de atividades comerciais e de serviços associam-se diretamente às iniciativas relativas à implantação dos loteamentos fechados" (SPOSITO, 2007, p. 7). 
Partiremos do pressuposto que os citadinos passam por um processo de autosegregação, como afirma Dal Pozzo (2008), os resultados desse processo, sobretudo, ao considerarmos as ações dos segmentos sociais de alto poder aquisitivo que optam pela autosegregação, são capazes de produzir uma efetiva descontinuidade territorial, tomando-se como referência a cidade, e uma apreensão parcelar do espaço urbano.

Em sentido estrito, a produção de novos habitats urbanos como os loteamentos fechados voltados, sobretudo, para atender a demanda dos segmentos sociais de alto poder aquisitivo, representam uma contribuição significativa para a consolidação dessa ruptura, acentuando o fenômeno da auto-segregação e produzindo uma apropriação diferenciada do espaço urbano (DAL POZZO, 2008, p. 20).

Os moradores desses novos habitats urbanos, geralmente, alcançam um elevado grau de integração espacial pelo uso expressivo do automóvel particular promovendo um alto nível de acessibilidade a vários equipamentos urbanos, servidos por vias de acesso rápidos e/ou a determinados setores urbanos voltados, sobretudo, para atender aos segmentos de alto poder aquisitivo (DAL POZZO, 2008).

Contudo, podemos ressaltar as disparidades existentes entre as zonas norte e sul da cidade de São José do Rio Preto, onde segundo Lima (2014), estas disparidades ocorrem desde meados de 1970 e 1980, com a implantação de bairros destinados à moradores de menor poder aquisitivo localizados na zona norte e, com a crescente implantação de condomínios residenciais de alto padrão na zona sul, o que por meio de trabalhos de campo pudemos constatar.

Um importante fator que consiste na reestruturação urbana de São José do Rio Preto é à saída do centro de uma população cujo poder aquisitivo é maior. Um movimento em direção à zona sul da cidade, resultando em um "abandono" do centro tradicional, gerando novas centralidades de acordo com a organização social, contudo resultando em uma segmentação social. "É possível observar um abandono do comércio de mais alto padrão da área central para os espaços mais exclusivos, que coincidem com os eixos principais em São José do Rio Preto, sobretudo a Sudoeste" (WHITACKER, 2003, p. 181).

Na cidade de São José do Rio Preto há duas avenidas que aparecem como as principais, sendo estas Bady Bassitt e Alberto Andaló. Ambas concentram empreendimentos de diversos segmentos, tais como, restaurantes, postos de gasolina com lojas de conveniência, farmácias, grandes redes de fast-food, bares, casas noturnas, etc. Estes estabelecimentos dão às avenidas uma centralidade no que concerne à oferta de consumo de bens e serviços. 
Conforme Sposito (2001, p. 237), as áreas centrais nas cidades atuam a partir de "um processo histórico de localização das atividades comerciais e de serviços no interior delas". Tal ação não é estática, e sim de diferenciados desenvolvimentos, dentre os quais: "ritmo de crescimento econômico e demográfico das cidades; formas de expansão dos tecidos urbanos relacionadas com seus sítios urbanos; instalação de novas infra-estruturas para circulação e emergência de novas formas de transporte" (SPOSITO, 2001, p. 237), etc. Contudo observamos que há uma difusão de áreas centrais com diferentes funções e conjuntos de valores. Sendo assim as Avenidas Bady Bassit e Alberto Andaló compartilham desta lógica, concentrando atividades de cunho comercial e de serviços.

Conforme afirma (CORRÊA, 2005, p. 5),

o interesse em conhecer e atuar sobre a cidade deriva do fato de ser ela o lugar onde vive parcela crescente da população. Mas também de ser o lugar onde os investimentos de capital são maiores, seja em atividades localizadas na cidade, seja no próprio urbano, na produção da cidade.

Portanto, percebemos que os interesses destes agentes estão, sobretudo, em áreas com grande fluxo de pessoas e podemos arriscar, com proximidades com empreendimentos do mesmo segmento (concorrência), tendo em vista o que foi observado em campo. 
Mapa 1. São José do Rio Preto - Localização das Avenidas Bady Bassit e Alberto Andaló.

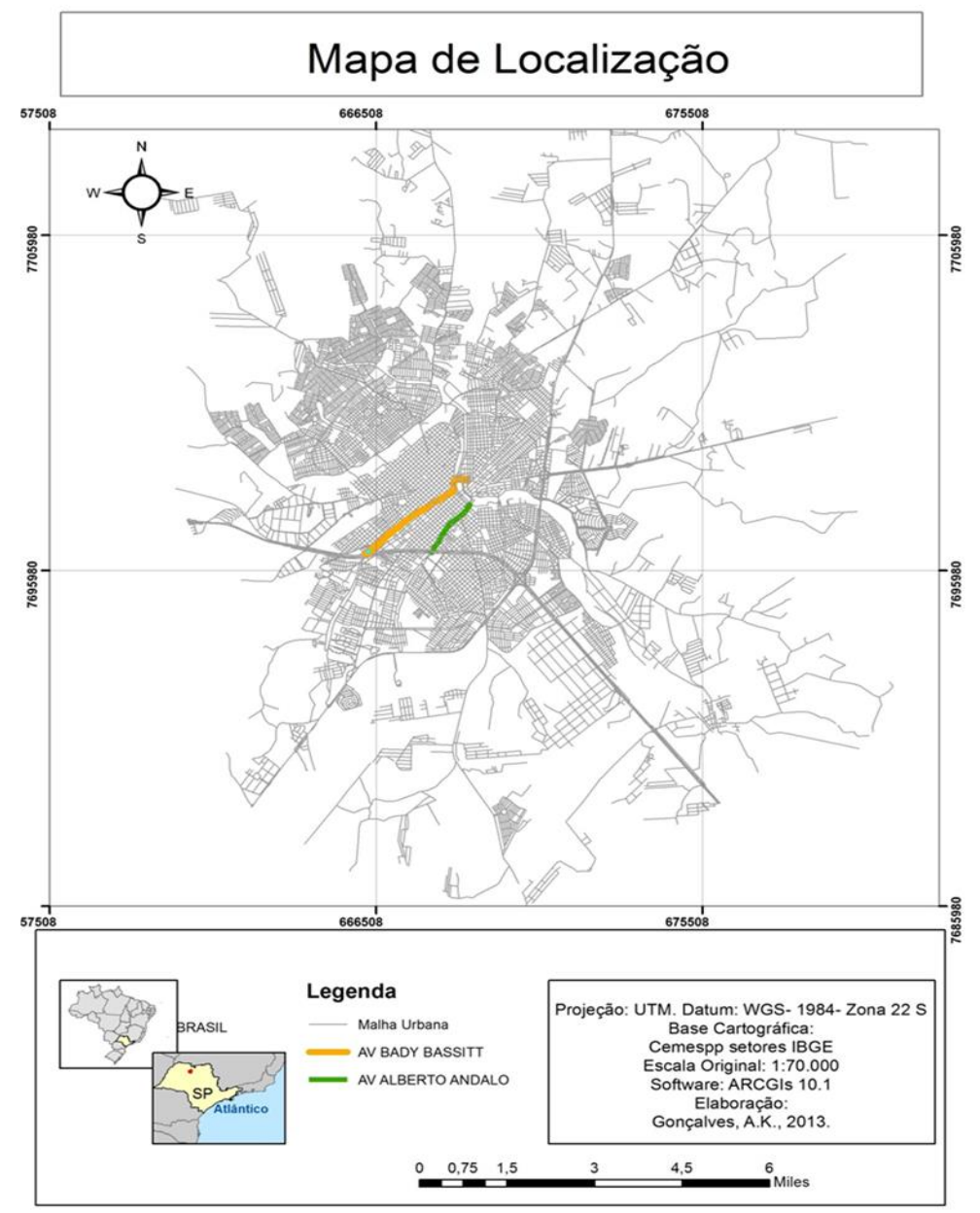

Fonte: Extraído de Sakurai, 2003.

Considerando as visitas a campo e as entrevistas com agentes bem informados, identificamos estas avenidas e o bairro Vila Redentora, também situada entre ambas, indo em direção à zona sul da cidade, como o que oferta um número significativo de empreendimentos de diversão noturna com tendência a uma maior concentração nos últimos anos.

Abaixo segue um mapa, que nos auxilia na localização deste bairro, demostrando um afastamento do centro indo em direção à zona sul, ainda expõe a concentração de bares que trabalham com a diversão noturna:

Mapa 2. São José do Rio Preto, 2014 - Áreas de Concentração de Estabelecimentos que ofertam Diversão Noturna. 


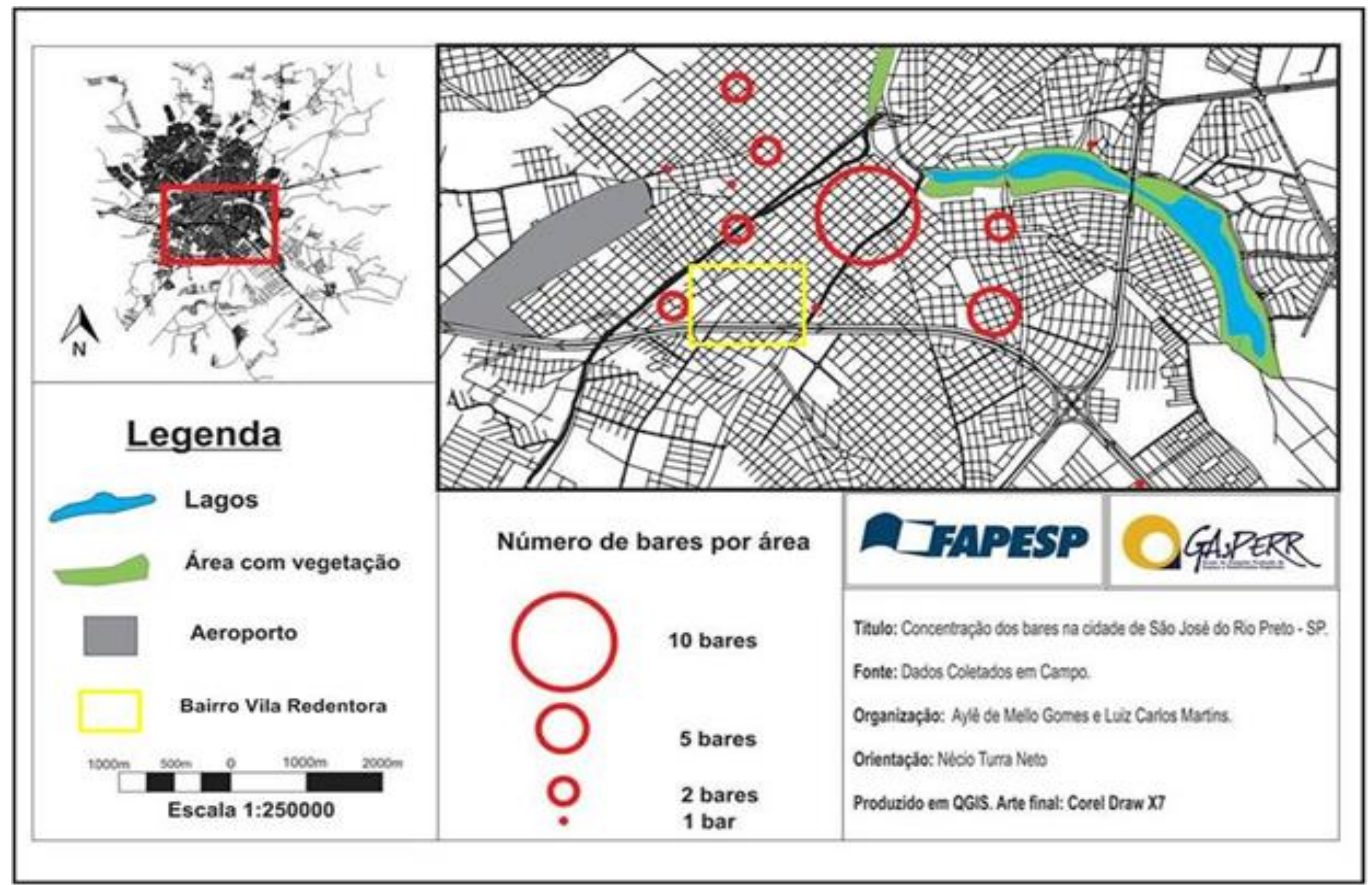

Fonte: GOMES, 2015

Portanto, áreas com público que possui maior poder aquisitivo atraem empreendedores da noite (no caso a zona sul). Destacamos também que esta segmentação na área da zona sul se explicita pelos processos de segregação e fragmentação socioespacial.

\section{CONSIDERAÇÕES FINAIS}

As cidades médias têm vivido um processo de multiplicação de suas áreas centrais, em decorrência da conjunção de capitais locais e daqueles que atuam em escalas regional, nacional e internacional. Tais centros marcam segmentações no plano das práticas espaciais e do mercado consumidor locais, expressando e reforçando clivagens sociais e potencializando novas.

A cidade de São José do Rio Preto oferece uma oferta maior de diversão noturna na região central, com ênfase nas avenidas Baddy Bassit e Alberto Andaló. Ainda podemos identificar indo em direção à zona sul da cidade, o bairro Vila Redentora como um novo pólo de diversão noturna, onde há bares, pubs e casas noturnas, com tendência à uma maior concentração.

Os estabelecimentos visitados (nas avenidas citadas e na Vila Redentora) visam o público com maior poder aquisitivo. Sua proximidade em relação aos novos produtos imobiliários (do tipo espaços residenciais fechados) indica que a lógica econômica dos 
agentes que oferecem vida noturna tende a reforçar o processo de fragmentação socioespacial, tal como identificado no texto de Dal Pozzo (2008).

Por fim destacamos também que esta segmentação na área da zona sul se explicita pelos processos de segregação e fragmentação socioespacial.

A zona norte da cidade não possui estabelecimentos que exercem uma centralidade quanto ao lazer noturno à escala da cidade, visto que não encontramos uma procura significativa dos frequentadores nesta área.

\section{REFERÊNCIAS}

ABRAMO, H. W. Cenas juvenis: punks e darks no espetáculo urbano. São Paulo: Editora Scritta, 1994.

ALMEIDA, M. I. M de; TRACY, K. M. de A. Noites nômades: espaço e subjetividade nas culturas jovens contemporâneas. Rio de Janeiro: Editora Rocco, 2003.

CALDEIRA, T. P. do R. Enclaves fortificados: a nova segregação urbana. Tradução de Heloísa Buarque de Almeida. Novos Estudos, n. 47, p. 155-176, 1997.

CERTAU, M. A Cultura no plural. 4. ed. Campinas/SP: Papirus Editora, 1995.

CORRÊA, R. L. O Espaço Urbano. São Paulo: Editora Ática, 2005.

DAL POZZO. C. F. Fragmentação socioespacial: Análise das práticas socioespaciais dos sujeitos auto-segregados em Presidente Prudente - SP. 2008. Dissertação (Mestrado em Geografia) - Universidade Estadual Paulista, 2008.

HAESBAERT, R. Território e Multiterritorialidade: um debate, GEOgraphia, Niterói, v. 9, n. 17, 2007.

HALL, S. A centralidade da cultura: notas sobre as revoluções culturais do nosso tempo. Educação \& Realidade, Porto Alegre, v. 22, n. 2, p. 15-46, jul./dez. 1997.

LIMA, L. H. M. Disparidades entre a zona sul e a zona norte de São José do Rio Preto/SP. 2014. Dissertação (Mestrado em Geografia) - Universidade Estadual Paulista, 2014.

PAIS, J. M. Culturas Juvenis. Lisboa: Imprensa Nacional - Casa da Moeda, 2003.

SANTOS, M. A natureza do espaço: técnica e tempo, razão e emoção. São Paulo: EDUSP, 2006.

SAKURAI, R. O consumo da mancha de lazer e sua centralidade: o caso da avenida Alberto Andaló. 2003.

SPOSITO, M. E. B. Novas formas comerciais e redefinição da centralidade intra-urbana. In SPOSITO, M. E. B. (Org.) Textos e contextos para a leitura geográfica de uma cidade média. Presidente Prudente: Programa de Pós-graduação em Geografia \& GAsPERR, 2001.

SPOSITO, M. E. B. Reestruturação urbana e segregação socioespacial no interior paulista. Revista electrónica de geografía y ciencias sociales, v. 11, n. 245, 2007. 
SPOSITO, M. P. A sociabilidade juvenil e a rua: novos conflitos e ação coletiva na cidade. Tempo Social, São Paulo, v. 5, n. 1-2, p. 161-178, 1993.

TURRA NETO, N. Enterrado vivo: identidade punk e território em Londrina. São Paulo: Ed. da UNESP, 2004.

WHITACKER, A. M. Reestruturação Urbana e Centralidade em São José do Rio Preto SP. 2003. 237.f. Tese (Doutorado em Geografia) - Faculdade de Ciência e Tecnologia - FCT Universidade estadual Paulista "Júlio de Mesquita Filho", Presidente Prudente, 2003.

WHITACKER, A. M. Centralidade, Morfologia e Reestruturação em Cidades Médias. Alguns elementos para o debate sobre as cidades médias brasileiras. In: VII Workshop da ReCiMe - Rede de Pesquisadores sobre Cidades Médias, 2010, Rio de Janeiro. VII Workshop da ReCiMe - Textos Temáticos. Presidente Prudente: ReCiMe, 2010. v. 1. p. 1-29. 